\title{
THE RESEARCH ON DYNAMIC CYCLE MONITORING OF TRANSFORMER SUBSTATION MODULAR DATA CENTRE CONFIGURATION BASED ON INTELLIGENT ASSISTANT
}

\author{
Zheng Liu ${ }^{1}$, Mingyang Ji ${ }^{1 *}$, Jing Chen ${ }^{2}$ \\ ${ }^{1}$ Beijing Fibrlink Communications Co., Ltd., Beijing 100070, China \\ ${ }^{2}$ State Grid Beijing Economic Research Institute, Beijing 100055, China \\ Email:jmk9en@126.com
}

\begin{abstract}
With the development of social production, higher requirements are put forward for the power grid transmission capacity; therefore, the power enterprises should continue to expand their power grid scale. The transformer substation is the basis of the expansion of the power grid scale, and the dynamic data monitoring of the transformer substation is the basis of the stable operation of the power grid. The intelligent auxiliary technology analysis dynamically monitors the distribution cabinet, UPS power supply, temperature and humidity, heat dissipation equipment, and alarm equipment of the transformer substation, and connects the data obtained with the data centre of the transformer substation to realize the intelligent management of the transformer substation. Due to the wide range of intelligent auxiliary technology, there are many dynamic cycle monitoring data in transformer substation, making real-time monitoring delay and leading to inaccurate data processing results. Rough sets optimize and improve the intelligent auxiliary technology through the simplified calculation method. Through data discovery, processing learning, expert system, and problem reasoning, the key information in dynamic cycle monitoring is found, and early warning information is sent to the management centre in time. The MATLAB simulation results show that the improved intelligent assistant technology can reduce 30 pieces of information in dynamic cycle monitoring and obtain 22 key data information. The data processing time is reduced by $20 \%$, and the accuracy of early warning information reaches $99.2 \%$. Therefore, the dynamic cycle monitoring effect of the improved intelligent auxiliary technology is better, and the processing speed is higher, which is suitable for the dynamic cycle monitoring of transformer substation modular data centre configuration.
\end{abstract}

Keywords: Rough Set; Intelligent Assistant, Parallel Reduction, Transformer Substation, Modular Data Centre, Dynamic Cycle Monitoring.

\section{Introduction}

The industrial structure has been adjusted constantly, resulting in the increasing number of transformer substations [1]. In order to improve the operation and maintenance efficiency of transformer substations, the modular central data processing method is adopted. A transformer substation involves power distribution cabinet, UPS power supply, temperature and humidity, heat dissipation equipment, alarm equipment, etc. Although the modular central data processing method can collect a large number of data, there are some problems in the processing process, such as a large amount of data and inaccurate processing results [2]. Intelligent auxiliary technology can solve the above problems and realize the dynamic cycle monitoring of transformer substation. However, long-term dynamic cycle monitoring will increase redundant data and affect the stability of dynamic cycle monitoring results. Therefore, it is necessary to optimize the intelligent auxiliary technology, reduce the amount of data processing, and improve the long-term effect of dynamic cycle monitoring. Rough sets can realize the uncertainty analysis of continuous data. Through data discovery, processing learning, expert system, and problem reasoning, it can simplify the data processing capacity of intelligent auxiliary technology and improve the accuracy of processing results. Guler et al. [3] proposed that a rough set based on modular judgment rules can achieve efficient result analysis and eliminate irrelevant, redundant data in a large number of continuous data. In the discrete data, rough sets can judge the key data, avoid the loss of key data and affect the accuracy of real-time monitoring results. Sengar and Mukhopadhyay [4] proposed that the bottleneck of the development of 
transformer substation intelligent auxiliary technology is a large amount of redundant information; thus, they improved the accuracy of data results using the optimization algorithm of data set and give full play to the advantages of intelligent auxiliary technology. Viola and Jones [5] proposed the integration of decision tree and intelligent auxiliary technology, used decision tree classification to determine the diagnosis regulation of transformer substation, and improved diagnosis accuracy. The results showed that the decision tree greatly improved the dynamic cycle monitoring effect of intelligent auxiliary technology. However, decision tree analysis is still based on a large number of redundant data, which cannot break through the negative effects of long-term redundancy. Therefore, this paper starts with the rough set and integrates it with intelligent auxiliary technology to give full play to their advantages and improve the dynamic cycle monitoring effect of transformer substation modular data centre configuration.

\section{Dynamic Cycle Monitoring}

Dynamic cycle monitoring realizes the intelligent management of transformer substations by dynamically monitoring the distribution cabinet, UPS power supply, temperature and humidity, heat dissipation equipment, and alarm equipment, and connecting the data obtained with the data centre of the transformer substation. Dynamic cycle monitoring needs to monitor the above objects, analyse the relationship between the monitoring objects, and form the data collection of each object [6].

(1) Monitoring objects. In the dynamic cycle monitoring, the monitoring objects belong to the classification range of data, which are classified according to the differences of their characteristics, to provide research scope for subsequent analysis.

(2) Indistinguishable relation. Objects with similar or indistinguishable features are classified into one category. There is more than one characteristic attribute of the data, and the different characteristic attributes of the two data are similar before they can be classified into one category. Indistinguishable relation is equivalent relation, which is used to describe the indistinguishable relationship between data.

(3) A modular dataset of individual objects. The modular data of each object is the collection of indistinguishable objects in the universe, and it is the constituent particle of domain knowledge. The basic set represents how many equivalent classes are contained in a universe or a series that reveals the attributes of an object.

(4) Modular data set of transformer substation. The modular data set of transformer substations is based on each object data set and integrates the classification object relationship to construct a set concept that meets the requirements of dynamic cycle monitoring. The set is divided into three cases, "fully compliant", "completely non-compliant", and "or compliant".

Therefore, the dynamic cycle monitoring can process the incomplete data of the distribution cabinet, UPS power supply, temperature and humidity, cooling equipment, alarm equipment, or data with many variables, and output the results that meet the requirements of transformer substations. Dynamic cycle monitoring obtains key data through continuous data elimination and logical reasoning.

\section{Transformer Substation}

Transformer substation refers to the place where the voltage and current are transformed to receive and distribute electric energy in the power system. The transformer substation in the power plant is a step-up transformer substation, whose function is to boost the power generated by the generator and feed it to the high-voltage power grid. The transformer substation is classified as:

(1) class I transformer substations, i.e., ultrahighvoltage alternating current stations, including nuclear power and large energy base-outgoing and inter-regional $750 \mathrm{kV}, 500 \mathrm{kV}$, and $330 \mathrm{kV}$ transformer substations;

(2) class II transformer substations, including other $750 \mathrm{kV}, 500 \mathrm{kV}$, and $330 \mathrm{kV}$ transformer substations except class I, power plant outgoing transformer substations, inter-provincial $220 \mathrm{kV}$ transformer substations, and substations causing level 4 or above power grid events induced by main transformer or bus outage and switch rejection;

(3) Class III transformer substations, including $220 \mathrm{kV}$ transformer substations except class II, power plant outgoing transformer substations, transformer substations causing level 5 power grid events induced by main transformer or bus outage and switch rejection, and transformer substations directly supplying power to important users of level I and above [7];

(4) class IV transformer substations, including 35 $\mathrm{kV}$ and above transformer substations except class I, II, and III.

The electrical equipment of the transformer substation is divided into primary equipment and secondary equipment. The following is a brief introduction to the main equipment in the transformer substation. Primary equipment refers to the equipment directly producing, transmitting, distributing, and using electric energy, mainly including transformer, high voltage circuit breaker, bus bar, arrester, capacitor, reactor, etc. The secondary equipment of transformer substation refers to the equipment for measuring, monitoring, controlling, and protecting the operating conditions 
of primary equipment and system. It mainly consists of a relay protection device, automatic device, measurement and control device, metering device, automation system, and DC equipment providing power for secondary equipment [8].

\section{Application of Intelligent Assistant in Transformer Substation}

\subsection{Quantification of Dynamic Cycle Monitoring with Intelligent Assistance}

According to the temperature and humidity of the power distribution cabinet, the intelligent power supply and humidity can be determined by calculating the temperature and humidity matrix of power distribution equipment. The application of intelligent auxiliary technology is as follows.

1) Suppose $M$ represents the identifiable matrix in the configuration of the data centre, and $S=1$ in the $M$ matrix, then it represents other data attributes other than the configuration data attribute, which cannot separate the two different substation judgment regulations, i.e., the attribute is a core attribute and cannot be removed. Suppose $C$ is the core attribute set of $C_{0}$. Before dynamic cycle monitoring, the $C$ set should be initialized, i.e., $C_{0}=C$.

2) Suppose $s$ represents the set of all data attribute combinations in $M$ matrix, and there is no duplicate attribute combination in $S$; suppose $S$ contains $n$ attribute combinations and is represented by $B_{i}$, which is formulated as that $B_{i}$ belongs to $S(\mathrm{i}=$ $1,2 \ldots, \mathrm{n})$. Suppose that $B_{i}$ contains $M$ conditional attribute and card $\left(B_{i}\right)=\mathrm{m}$, its formulaic description is that $b_{i j}$ belongs to $b_{i}(i=1,2, \ldots, \mathrm{n}) ; j=(1,2, \ldots, \mathrm{m})$; card $(*)$ is the cardinality of the set. The attribute combination $\mathrm{Q}$ of non-kernel attributes is found in the discernibility matrix, which is formulated as follows:

$$
\left\{\begin{array}{c}
Q=\left\{B_{i j}: B_{i} \cap B_{j} \neq \Pi, \subset S(i=1,2, \cdots, n)\right\} \\
S_{\text {non }}=S-Q
\end{array}\right.
$$

3) By transforming $S$ set into conjunctive normal form, $P$ is formulated as:

$$
S=\cup\left\{\cap B_{i j}(i=1,2, \cdots, n ; j=1,2, \cdots, m)\right\}
$$

4) The disjunctive normal form $P$ is transformed into disjunctive normal form:

$$
P=\notin\left\{\cap B_{i j}(i=1,2, \cdots, n ; j=1,2, \cdots, m)\right\}
$$

\subsection{Application Principles of Intelligent Assistance}

Rule extraction is not only the regulation of intelligent auxiliary to dynamic cycle monitoring of substation but also the key of configuration processing of modular data centre [9].

However, the results of intelligent aided dynamic cycle monitoring are easily affected by equipment operation status, natural factors, and human factors. An intelligent assistant can classify and regress the data of power distribution cabinet, UPS power supply, temperature and humidity, heat dissipation equipment, and alarm equipment by using the theory of information entropy reduction. It can determine the relationship between data attributes under different conditions and realize the extraction of dynamic cycle monitoring rules [10]. The intelligent assistant takes the sample data as the node, takes the data attributes such as power distribution cabinet, UPS power supply, temperature and humidity, heat dissipation equipment, alarm equipment as branches, and finally obtains the dynamic cycle monitoring results. Starting from the configuration of modular data centre of the substation, the power distribution cabinet, UPS power supply, temperature and humidity, heat dissipation equipment, and alarm equipment are monitored in turn. The equipment is set with judgment conditions, the configuration status of the substation is fed back according to the judgment results, and the results are returned to the modular data centre.

\subsection{Dynamic Cycle Monitoring Process of Data Centre Configuration}

Definition 1: suppose $U$ represents the collection of monitoring data sent by the configuration point to the data centre, $\mathrm{u}_{\mathrm{i}}(\mathrm{i}=1,2, \cdots, \mathrm{i})$ is the monitoring data at different time points, which is formulated as:

$$
U_{\text {tot le }}=\left(u_{1}, u_{2}, \cdots, u_{i}\right)
$$

Suppose $V$ represents the set of configuration point data accepted by the data centre, $v_{j}(i=1,2, \cdots, j)$ is the monitoring data received at different time points, which is formulated as:

$$
V_{\text {tot le }}=\left(v_{1}, v_{2}, \cdots, v_{j}\right)
$$

Suppose that $\mathrm{P}=\left(\mathrm{u}_{\mathrm{i}}\right)$ is the amount of data sent out by each configuration point, and $\mathrm{P}=\left(\mathrm{u}_{\mathrm{i}} / \mathrm{v}_{\mathrm{i}}\right)$ is the received data volume/generated data volume, i.e., the accuracy probability of monitoring information, which is formulated as:

$$
H(U)=-\sum P\left(u_{i}\right) \log _{n} P\left(u_{i}\right)
$$

The uncertainty of all monitoring information received by the data centre, i.e., the accuracy of all monitoring information, is: 


$$
H(U / V)=-\sum_{j} P\left(v_{j}\right) \sum_{i} P\left(u_{i} \mid v_{i}\right) \log _{n} P\left(u_{i} / v_{j}\right)
$$

The value of the logarithm base $n$ determines the unit of information.

Definition 2: after the data centre receives the monitoring information $V$, the attribute information quantity $Q$ of the non-nuclear attribute of the information quantity $U$ sent by the configuration point is calculated:

$$
Q_{\mathrm{totle}}=H\left(U_{i}\right)-H\left(U_{i} / V_{i}\right)
$$

$\mathrm{Q}$ represents the amount of information $V$ can provide about $U$.

\subsection{Application Steps of Intelligent Assistance}

In the process of distribution network fault diagnosis, the fault diagnosis steps are as follows.

1) For the condition attribute $S$ in the alarm signal $U$ of the fault point;

2) According to the order of conditional entropy $P$, the greater the value of $P$ is, the smaller the degree of uncertainty is, and the higher the criticality of its attributes is. When the value of $P$ is larger than the pre-set threshold value, it can be included in 1- $Q$ of the core attribute set to reduce the amount of fault alarm information.

3) If the fault alarm information is matched with the diagnosis rules, the distribution fault diagnosis results based on rough set parallel reduction can be obtained, and the results will be included in the fault set; otherwise, return to step 2.

4) The information of the branch in the decision tree is searched, and the result is output; otherwise, return to step 2 .

\begin{tabular}{|c|c|c|c|c|c|c|c|c|c|c|c|c|c|c|}
\hline NO & UPS & $\begin{array}{l}\text { Distribution } \\
\text { Cabinet } 5\end{array}$ & $\begin{array}{l}\text { Distribution } \\
\text { Cabinet } 6\end{array}$ & $\begin{array}{l}\text { Distribution } \\
\text { Cabinet } 7\end{array}$ & \begin{tabular}{|l} 
Distribution \\
Cabinet 8
\end{tabular} & $\begin{array}{l}\text { Temperature } \\
3\end{array}$ & Temperature & $\begin{array}{l}\text { Heat } \\
\text { Dissipation } \\
\text { Equipment } \\
1\end{array}$ & $\begin{array}{l}\text { Heat } \\
\text { Dissipation } \\
\text { Equipment } \\
2\end{array}$ & \begin{tabular}{|l|} 
Heat \\
Dissipation \\
Equipment \\
3
\end{tabular} & $\begin{array}{l}\text { Heat } \\
\text { Dissipation } \\
\text { Equipment } \\
4\end{array}$ & $\begin{array}{l}\text { Configuration } \\
\text { Centre } 1\end{array}$ & $\begin{array}{l}\text { Configuration } \\
\text { Centre 2 }\end{array}$ & Monitor \\
\hline A & $\mathrm{F}$ & $\mathrm{F}$ & $\mathrm{F}$ & $\mathrm{F}$ & $\mathrm{F}$ & $\mathrm{F}$ & $\mathrm{F}$ & $\mathrm{F}$ & $\mathrm{F}$ & $\mathrm{F}$ & $\mathrm{F}$ & $\mathrm{F}$ & $\mathrm{F}$ & 1 \\
\hline$B$ & $\mathrm{~F}$ & $\mathrm{~F}$ & $\mathrm{~F}$ & $\mathrm{~F}$ & $\mathrm{~F}$ & $F$ & $F$ & $\mathrm{~F}$ & $\mathrm{~F}$ & $\mathrm{~F}$ & $\mathrm{~F}$ & $\mathrm{~T}$ & $\mathrm{~F}$ & Bus1 \\
\hline $\mathrm{C}$ & $\mathrm{F}$ & $\mathrm{F}$ & $\mathrm{F}$ & $\mathrm{F}$ & $\mathrm{F}$ & $\mathrm{F}$ & $\mathrm{F}$ & $\mathrm{F}$ & $\mathrm{F}$ & $\mathrm{F}$ & $\mathrm{F}$ & $\mathrm{F}$ & $\mathrm{T}$ & Bus1 \\
\hline $\mathrm{D}$ & $\mathrm{F}$ & $\mathrm{F}$ & $\mathrm{F}$ & $\mathrm{F}$ & $\mathrm{F}$ & $F$ & $\mathrm{~F}$ & $\mathrm{~F}$ & $\mathrm{~F}$ & $\mathrm{~F}$ & $\mathrm{~F}$ & $\mathrm{~F}$ & $\mathrm{~T}$ & Bus2 \\
\hline$E$ & $\mathrm{~T}$ & $\mathrm{~F}$ & $\mathrm{~F}$ & $\mathrm{~F}$ & $\mathrm{~F}$ & $\mathrm{~F}$ & $\mathrm{~F}$ & $\mathrm{~F}$ & $\mathrm{~F}$ & $\mathrm{~F}$ & $\mathrm{~F}$ & $\mathrm{~T}$ & $\mathrm{~F}$ & Bus2 \\
\hline $\mathrm{F}$ & $\mathrm{F}$ & $\mathrm{F}$ & $\mathrm{F}$ & $\mathrm{F}$ & $\mathrm{F}$ & $\mathrm{T}$ & $\mathrm{F}$ & $\mathrm{F}$ & $\mathrm{F}$ & $\mathrm{F}$ & $\mathrm{F}$ & $\mathrm{F}$ & $\mathrm{F}$ & L1 \\
\hline$G$ & $\mathrm{~F}$ & $\mathrm{~F}$ & $\mathrm{~F}$ & $\mathrm{~F}$ & $\mathrm{~F}$ & $\mathrm{~F}$ & $\mathrm{~T}$ & $\mathrm{~F}$ & $\mathrm{~F}$ & $\mathrm{~F}$ & $\mathrm{~F}$ & $\mathrm{~F}$ & $\mathrm{~F}$ & L2 \\
\hline $\mathrm{H}$ & $\mathrm{F}$ & $\mathrm{F}$ & $\mathrm{T}$ & $\mathrm{F}$ & $\mathrm{F}$ & $F$ & $\mathrm{~F}$ & $F$ & $\mathrm{~F}$ & $\mathrm{~F}$ & $\mathrm{~F}$ & $\mathrm{~F}$ & $\mathrm{~F}$ & L3 \\
\hline I & $\mathrm{F}$ & $\mathrm{F}$ & $\mathrm{F}$ & $\mathrm{T}$ & $\mathrm{F}$ & $\mathrm{F}$ & $\mathrm{F}$ & $\mathrm{F}$ & $\mathrm{F}$ & $\mathrm{F}$ & $\mathrm{F}$ & $\mathrm{F}$ & $\mathrm{F}$ & L4 \\
\hline $\mathrm{J}$ & $\mathrm{F}$ & $\mathrm{F}$ & $\mathrm{F}$ & $\mathrm{F}$ & $\mathrm{F}$ & $\mathrm{F}$ & $\mathrm{F}$ & $\mathrm{T}$ & $\mathrm{F}$ & $\mathrm{F}$ & $\mathrm{F}$ & $\mathrm{F}$ & $\mathrm{F}$ & $\mathrm{T} 1$ \\
\hline $\mathrm{K}$ & $\mathrm{F}$ & $\mathrm{F}$ & $\mathrm{F}$ & $\mathrm{F}$ & $\mathrm{F}$ & $\mathrm{F}$ & $\mathrm{F}$ & $\mathrm{F}$ & $\mathrm{T}$ & $\mathrm{F}$ & $\mathrm{F}$ & $\mathrm{F}$ & $\mathrm{F}$ & $\mathrm{T} 2$ \\
\hline $\mathrm{L}$ & $\mathrm{F}$ & $\mathrm{F}$ & $\mathrm{F}$ & $\mathrm{F}$ & $\mathrm{F}$ & $\mathrm{F}$ & $\mathrm{F}$ & $\mathrm{F}$ & $\mathrm{F}$ & $\mathrm{F}$ & $\mathrm{F}$ & $\mathrm{F}$ & $\mathrm{F}$ & T3 \\
\hline $\mathrm{M}$ & $\mathrm{T}$ & $\mathrm{T}$ & $\mathrm{F}$ & $\mathrm{F}$ & $\mathrm{F}$ & $\mathrm{F}$ & $\mathrm{F}$ & $\mathrm{F}$ & $\mathrm{F}$ & $\mathrm{F}$ & $\mathrm{F}$ & $\mathrm{F}$ & $\mathrm{F}$ & $\mathrm{T} 4$ \\
\hline $\mathrm{N}$ & $\mathrm{F}$ & $\mathrm{F}$ & $\mathrm{F}$ & $\mathrm{F}$ & $\mathrm{F}$ & $\mathrm{F}$ & $\mathrm{F}$ & $\mathrm{F}$ & $\mathrm{F}$ & $\mathrm{T}$ & $\mathrm{F}$ & $\mathrm{F}$ & $\mathrm{F}$ & Sce1 \\
\hline 0 & $\mathrm{~F}$ & $\mathrm{~F}$ & $\mathrm{~F}$ & $\mathrm{~F}$ & $\mathrm{~F}$ & $\mathrm{~F}$ & $\mathrm{~F}$ & $\mathrm{~F}$ & $\mathrm{~F}$ & $\mathrm{~F}$ & $\mathrm{~T}$ & $\mathrm{~F}$ & $\mathrm{~F}$ & Sce2 \\
\hline $\mathrm{P}$ & $\mathrm{F}$ & $\mathrm{F}$ & $\mathrm{F}$ & $\mathrm{F}$ & $\mathrm{T}$ & $\mathrm{F}$ & $\mathrm{T}$ & $\mathrm{F}$ & $\mathrm{F}$ & $\mathrm{F}$ & $\mathrm{F}$ & $\mathrm{F}$ & $\mathrm{F}$ & Sce3 \\
\hline
\end{tabular}

Table 1. Configuration of Substation Modular Data Centre Based on Intelligent Auxiliary

\section{Experimental Analysis}

In order to verify the dynamic cycle monitoring effect of intelligent assistant on substation modular data centre configuration, the following analysis is carried out.

\subsection{Index Determination}

In the substation modular data centre configuration, dynamic cycle monitoring data is collected, and the data comes from two aspects. On the one hand, the normal information of configuration equipment such as power distribution cabinet, UPS power supply, temperature and humidity, cooling equipment, and alarm equipment is "completely belong to the collection"; on the other hand, the warning information such as distribution cabinet, UPS power supply, temperature and humidity, cooling equipment, alarm equipment, etc. is "not in the collection at all" and "or belong to the collection".

\subsection{Initialization of Data Centre Configuration Table}

According to $(1) \sim(3)$, the configuration table C of the fault and data centre is initialized, and the condition attribute reduction is realized. The 30 condition attributes are reduced to 22. Fifteen representative fault points, namely substation, UPS, temperature 3 , heat dissipation equipment $1 \sim 2$ and configuration centre $1 \sim 2$, are selected as fault sets $u_{22}(1,2, \cdots 22)$, and the corresponding table is constructed by their reduced attributes, shown in Table 1. 
According to (4) (8), the rules, initial entropy, and conditional entropy of dynamic cycle monitoring are proposed. The results are shown in Table 2.

\subsection{Calculation of Conditional Entropy}

Based on Table 1 and (4) (8), the conditional entropy when the initial entropy is 1.0432 can be obtained.
By judging the attributes of substation, UPS $\sim 8$, temperature 3 , heat dispersion equipment $1 \sim 2$ and BR1 2, the conditional entropy values under 1.036 and 0.271 are obtained, and the corresponding decision tree is drawn.

The calculation results of initial entropy and attribute condition entropy are shown in Table 2.

Table 2. Calculation Results of Initial Entropy and Attribute Condition Entropy

\begin{tabular}{|c|c|c|c|c|c|c|c|c|c|c|c|c|c|}
\hline \multirow[t]{2}{*}{ Normal } & UPS & \begin{tabular}{|l|} 
Distribution \\
Cabinet 5
\end{tabular} & \begin{tabular}{|l|} 
Distribution \\
Cabinet 6
\end{tabular} & \begin{tabular}{|l} 
Distribution \\
Cabinet 7
\end{tabular} & $\begin{array}{l}\text { Distribution } \\
\text { Cabinet } 8\end{array}$ & Temperature 3 & Temperature 4 & $\begin{array}{l}\text { Heat } \\
\text { Dissipation } \\
\text { Equipment1 }\end{array}$ & \begin{tabular}{|l|} 
Heat \\
Dissipation \\
Equipment2
\end{tabular} & \begin{tabular}{|l|} 
Heat \\
Dissipation \\
Equipment3
\end{tabular} & \begin{tabular}{|l|} 
Heat \\
Dissipation \\
Equipment4
\end{tabular} & $\begin{array}{l}\text { Configuration } \\
\text { Center1 }\end{array}$ & $\begin{array}{l}\text { Configuration } \\
\text { Center2 }\end{array}$ \\
\hline & 0.936 & 0.996 & 0.958 & 0.958 & 0.958 & 0.958 & 0.958 & 0.957 & 0.996 & 0.996 & 0.957 & 0.957 & 0.996 \\
\hline \multirow[t]{2}{*}{$\begin{array}{l}\text { Substation= } \\
0\end{array}$} & UPS & \begin{tabular}{|l|} 
Distribution \\
Cabinet 5
\end{tabular} & \begin{tabular}{|l|} 
Distribution \\
Cabinet 6
\end{tabular} & \begin{tabular}{|l} 
Distribution \\
Cabinet 7
\end{tabular} & $\begin{array}{l}\text { Distribution } \\
\text { Cabinet } 8\end{array}$ & Temperature & Temperature & \begin{tabular}{|l|} 
Heat \\
Dissipation \\
Equipment1
\end{tabular} & \begin{tabular}{|l|} 
Heat \\
Dissipation \\
Equipment2
\end{tabular} & \begin{tabular}{|l|} 
Heat \\
Dissipation \\
2 Equipment3
\end{tabular} & \begin{tabular}{|l|} 
Heat \\
Dissipation \\
3 Equipment
\end{tabular} & 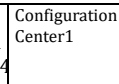 & \begin{tabular}{|l|}
$\begin{array}{l}\text { Configuration } \\
\text { Center2 }\end{array}$ \\
\end{tabular} \\
\hline & 0.727 & 0.917 & 0.910 & 0.910 & 0.910 & 0.910 & 0.910 & 0.910 & 0.917 & 0.910 & 0.910 & 1.036 & 0.910 \\
\hline \multirow[t]{2}{*}{$\begin{array}{l}\text { Substation } \\
=0, \text { UPS }=0\end{array}$} & UPS & \begin{tabular}{|l|} 
Distribution \\
Cabinet 5
\end{tabular} & \begin{tabular}{|l|} 
Distribution \\
Cabinet 6
\end{tabular} & \begin{tabular}{|l} 
Distribution \\
Cabinet 7
\end{tabular} & $\begin{array}{l}\text { Distribution } \\
\text { Cabinet } 8\end{array}$ & Temperature 3 & Temperature 4 & $\begin{array}{l}\text { Heat } \\
\text { Dissipation } \\
\text { Equipment }\end{array}$ & \begin{tabular}{|l|} 
Heat \\
Dissipation \\
Equipment:
\end{tabular} & \begin{tabular}{|l|} 
Heat \\
Dissipation \\
Equipment
\end{tabular} & \begin{tabular}{|l|} 
Heat \\
Dissipation \\
Equipment
\end{tabular} & $\begin{array}{ll} & \text { Configuration } \\
\text { Center1 }\end{array}$ & \begin{tabular}{|l|}
$\begin{array}{l}\text { Configuration } \\
\text { Center2 }\end{array}$ \\
\end{tabular} \\
\hline & NULL & 0.011 & 0.222 & 0.222 & 0.222 & 0.222 & 0.222 & 0.222 & 0.222 & 0.222 & 0.222 & 0.222 & 0.222 \\
\hline \multirow{2}{*}{$\begin{array}{l}\text { Substation, } \\
\text { UPS, } 6,7,7 \text {, } \\
\text { temperature } \\
3,4 \text {, heat } \\
\text { dissipation } \\
\text { equipment } 2 \text {, } \\
3,4 \text {, } \\
\text { configuration } \\
\text { centre } 2=0\end{array}$} & UPS & \begin{tabular}{|l|} 
Distribution \\
Cabinet 5
\end{tabular} & \begin{tabular}{|l|} 
Distribution \\
Cabinet 6
\end{tabular} & \begin{tabular}{|l} 
Distribution \\
Cabinet 7
\end{tabular} & \begin{tabular}{|l|} 
Distribution \\
Cabinet 8
\end{tabular} & Temperature & Temperature & \begin{tabular}{|l|} 
Heat \\
Dissipation \\
Equipment1
\end{tabular} & \begin{tabular}{|l|} 
Heat \\
Dissipation \\
Equipment2
\end{tabular} & \begin{tabular}{|l|} 
Heat \\
Dissipation \\
Equipment3 \\
\end{tabular} & \begin{tabular}{|l|} 
Heat \\
Dissipation \\
3 Equipment4 \\
\end{tabular} & \begin{tabular}{|l}
$\begin{array}{l}\text { Configuration } \\
\text { Center1 }\end{array}$ \\
\end{tabular} & \begin{tabular}{|l|l}
$\begin{array}{l}\text { Configuration } \\
\text { Center2 }\end{array}$ \\
\end{tabular} \\
\hline & NULL & 0.271 & NULL & NULL & NULL & NULL & NULL & 0.302 & NULL & NULL & NULL & 0.271 & NULL \\
\hline
\end{tabular}

\subsection{Comparison of Test Results}

- Simulation diagnostic configuration centre for setpoints

The condition attributes of substation, UPS $\sim 7$, temperature 3 , heat departure equipment $1 \sim 4$ and configuration centre $1 \sim 2$ are calculated, and the missing items of sample fault information are left out. The simulation results are shown in Table 3.

Table 3. Dynamic Cycle Monitoring Results of Substation Modular Data Centre Configuration Based on Intelligent

\begin{tabular}{|c|c|c|c|c|c|c|c|c|c|c|c|c|c|c|c|}
\hline No & Position & & \begin{tabular}{|l}
$\begin{array}{l}\text { Distribution } \\
\text { Cabinet } 5\end{array}$ \\
\end{tabular} & $\begin{array}{l}\text { Distribution } \\
\text { Cabbinet } 6\end{array}$ & $\begin{array}{l}\text { Distribution } \\
\text { Cabinet } 7\end{array}$ & \begin{tabular}{|l|} 
Distribution \\
Cabinet 7
\end{tabular} & $\mid \begin{array}{l}\text { Temperature } \\
3\end{array}$ & \begin{tabular}{|l|} 
Temperature \\
4
\end{tabular} & \begin{tabular}{|l|} 
Heat \\
Dissipation \\
Equipment1
\end{tabular} & \begin{tabular}{|l|}
$\begin{array}{l}\text { Heat } \\
\text { Dissipation } \\
\text { Equipment2 }\end{array}$ \\
\end{tabular} & $\begin{array}{l}\text { Heat } \\
\text { Dissipation } \\
\text { Equipment3 }\end{array}$ & \begin{tabular}{|l}
$\begin{array}{l}\text { Heat } \\
\text { Dissipation } \\
\text { Eqquipment4 }\end{array}$ \\
\end{tabular} & $\begin{array}{l}\text { Configuration } \\
\text { Center1 }\end{array}$ & \begin{tabular}{|l} 
Configuration \\
Center2
\end{tabular} & Monitor \\
\hline 1 & N- & $\mathrm{N}$ & $\mathrm{N}$ & $\mathrm{N}$ & $\mathrm{N}$ & $\mathrm{N}$ & $\mathrm{N}$ & $\mathrm{N}$ & $\mathrm{N}$ & $\mathrm{N}$ & $\mathrm{N}$ & $\mathrm{N}$ & $\mathrm{N}$ & $\mathrm{N}$ & N- \\
\hline 2 & $\begin{array}{l}\text { Bus } \\
1\end{array}$ & $\mathrm{~N}$ & $\mathrm{~N}$ & $\mathrm{~N}$ & $\mathrm{~N}$ & D & $\mathrm{N}$ & $\mathrm{N}$ & $\mathrm{N}$ & $\mathrm{N}$ & $\mathrm{N}$ & $\mathrm{N}$ & $\mathrm{T}$ & $\mathrm{N}$ & Bus1 \\
\hline 3 & $\begin{array}{l}\text { Bus } \\
1\end{array}$ & $\mathrm{~N}$ & $\mathrm{~N}$ & D & $\mathrm{N}$ & $\mathrm{N}$ & $\mathrm{N}$ & $\mathrm{N}$ & D & D & $\mathrm{N}$ & $\mathrm{N}$ & $\mathrm{N}$ & $\mathrm{T}$ & Bus1 \\
\hline 4 & $\begin{array}{l}\text { Bus } \\
2\end{array}$ & $\mathrm{~N}$ & $\mathrm{~N}$ & D & D & $\mathrm{N}$ & $\mathrm{N}$ & D & $\mathrm{N}$ & $\mathrm{N}$ & D & D & $\mathrm{N}$ & $\mathrm{T}$ & $\begin{array}{l}\text { Bus2/ } \\
\text { L2 }\end{array}$ \\
\hline 5 & $\begin{array}{l}\text { Bus } \\
2\end{array}$ & $\mathrm{~T}$ & $\mathrm{~N}$ & $\mathrm{~N}$ & D & $\mathrm{N}$ & D & $\mathrm{N}$ & $\mathrm{N}$ & D & $\mathrm{N}$ & $\mathrm{N}$ & $\mathrm{T}$ & $\mathrm{N}$ & Bus2 \\
\hline 6 & L1 & $\mathrm{N}$ & $\mathrm{N}$ & $\mathrm{N}$ & $\mathrm{N}$ & $\mathrm{N}$ & $\mathrm{T}$ & $\mathrm{N}$ & $\mathrm{N}$ & $\mathrm{N}$ & $\mathrm{N}$ & $\mathrm{N}$ & $\mathrm{N}$ & $\mathrm{N}$ & L1 \\
\hline 7 & L2 & $\mathrm{N}$ & $\mathrm{D}$ & $\mathrm{D}$ & $\mathrm{N}$ & $\mathrm{N}$ & $\mathrm{N}$ & $\mathrm{T}$ & $\mathrm{N}$ & $\mathrm{N}$ & $\mathrm{N}$ & $\mathrm{N}$ & $\mathrm{N}$ & $\mathrm{N}$ & L2 \\
\hline 7 & L3 & $\mathrm{N}$ & $\mathrm{N}$ & $\mathrm{T}$ & $\mathrm{N}$ & D & $\mathrm{N}$ & $\mathrm{N}$ & $\mathrm{N}$ & $\mathrm{N}$ & $\mathrm{N}$ & $\mathrm{N}$ & $\mathrm{N}$ & $\mathrm{N}$ & L3 \\
\hline 9 & L4 & $\mathrm{N}$ & D & $\mathrm{N}$ & $\mathrm{T}$ & D & D & D & $\mathrm{N}$ & D & $\mathrm{N}$ & $\mathrm{N}$ & $\mathrm{N}$ & $\mathrm{N}$ & L4 \\
\hline 10 & T1 & $\mathrm{N}$ & $\mathrm{D}$ & $\mathrm{N}$ & $\mathrm{N}$ & $\mathrm{N}$ & $\mathrm{N}$ & $\mathrm{N}$ & $\mathrm{T}$ & $\mathrm{N}$ & $\mathrm{D}$ & D & $\mathrm{D}$ & $\mathrm{D}$ & $\mathrm{T} 1$ \\
\hline 22 & T2 & $\mathrm{N}$ & $\mathrm{N}$ & $\mathrm{N}$ & $\mathrm{N}$ & $\mathrm{N}$ & $\mathrm{N}$ & $\mathrm{N}$ & $\mathrm{N}$ & $\mathrm{T}$ & $\mathrm{N}$ & $\mathrm{N}$ & $\mathrm{N}$ & $\mathrm{N}$ & $\mathrm{T} 2$ \\
\hline 12 & T3 & $\mathrm{N}$ & $\mathrm{N}$ & $\mathrm{N}$ & $\mathrm{D}$ & $\mathrm{N}$ & $\mathrm{N}$ & $\mathrm{N}$ & $\mathrm{N}$ & $\mathrm{N}$ & $\mathrm{N}$ & $\mathrm{N}$ & $\mathrm{N}$ & $\mathrm{N}$ & T3 \\
\hline 13 & T4 & $\mathrm{T}$ & $\mathrm{T}$ & $\mathrm{N}$ & $\mathrm{N}$ & D & $\mathrm{N}$ & $\mathrm{N}$ & $\mathrm{N}$ & $\mathrm{N}$ & $\mathrm{N}$ & $\mathrm{N}$ & $\mathrm{N}$ & $\mathrm{N}$ & $\mathrm{T} 4$ \\
\hline
\end{tabular}




\begin{tabular}{|c|c|c|c|c|c|c|c|c|c|c|c|c|c|c|c|}
\hline No & Position & & $\begin{array}{l}\text { Distribution } \\
\text { Cabinet } 5\end{array}$ & \begin{tabular}{|l} 
Distribution \\
Cabinet 6
\end{tabular} & $\begin{array}{l}\text { Distribution } \\
\text { Cabinet } 7\end{array}$ & $\begin{array}{l}\text { Distribution } \\
\text { Cabinet } 7\end{array}$ & $\begin{array}{l}\text { Temperature } \\
3\end{array}$ & $\begin{array}{l}\text { Temperature } \\
4\end{array}$ & $\begin{array}{l}\text { Heat } \\
\text { Dissspation } \\
\text { Equipment1 }\end{array}$ & $\begin{array}{l}\text { Heat } \\
\text { Dissipation } \\
\text { Equipment2 }\end{array}$ & $\begin{array}{l}\text { Heat } \\
\text { Dissipation } \\
\text { Equipment3 }\end{array}$ & $\begin{array}{l}\text { Heat } \\
\text { Dissipation } \\
\text { Equipment4 }\end{array}$ & \begin{tabular}{|l|} 
Configuration \\
Center1
\end{tabular} & $\begin{array}{l}\text { Configuration } \\
\text { Center2 }\end{array}$ & Monitor \\
\hline 14 & Sce1 & $\mathrm{N}$ & $\mathrm{N}$ & $\mathrm{N}$ & $\mathrm{N}$ & D & D & $\mathrm{N}$ & $\mathrm{N}$ & $\mathrm{N}$ & $\mathrm{T}$ & $\mathrm{N}$ & $\mathrm{N}$ & $\mathrm{N}$ & Sce1 \\
\hline 15 & Sce2 & $\mathrm{N}$ & $\mathrm{N}$ & $\mathrm{N}$ & $\mathrm{N}$ & D & $\mathrm{N}$ & $\mathrm{N}$ & $\mathrm{N}$ & $\mathrm{N}$ & $\mathrm{N}$ & $\mathrm{T}$ & $\mathrm{N}$ & $\mathrm{N}$ & Sce2 \\
\hline 16 & Sce3 & $\mathrm{D}$ & D & $\mathrm{N}$ & $\mathrm{N}$ & $\mathrm{D}$ & $\mathrm{N}$ & $\mathrm{T}$ & $\mathrm{N}$ & D & D & D & $\mathrm{N}$ & $\mathrm{N}$ & $\begin{array}{l}\text { Sce3/T } \\
4\end{array}$ \\
\hline
\end{tabular}

It can be seen from Table 3 that the fault diagnosis of samples 4 and 16 is mainly due to the loss of distribution cabinet 6 , distribution cabinet 7 , temperature 4, TR3 and 4 in sample 4 , and UPS $\sim 5$, distribution cabinet 8 and TR2 $\sim 4$ in sample 16 .

The number of missing kernel attributes in 4 and 16 samples is more than $50 \%$; therefore, there is a deviation. However, the deviation of dynamic cycle monitoring results of samples 4 and 16 only expands the range, which increases the diagnosis of $\mathrm{L} 2$ and T4 points, respectively, and there is no error in dynamic cycle monitoring results. On the whole, the dynamic cycle monitoring effect is relatively ideal.

\section{efficiency \\ - Comparison of algorithm accuracy and}

1. Comparing the dynamic cycle monitoring method based on intelligent auxiliary modular data centre configuration with the traditional dynamic cycle monitoring method, it is found that the accuracy of the former can reach $99.2 \%$ under 1500 iterations, while the latter can only reach $91.2 \%$. The former is significantly better than the latter. The error rate of the dynamic cycle monitoring method based on intelligent auxiliary substation modular data centre configuration is relatively stable, and the overall error rate is about $6.5 \%$. The error rate of the traditional dynamic cycle monitoring method continues to rise. At 1000 iterations, the error rate rises rapidly, and the late error rate remains stable, with an overall error rate of $13.4 \%$.

2. The dynamic cycle monitoring method based on intelligent assistance has 1500 iterations, which is only $75 \mathrm{~s}$, while the traditional dynamic cycle monitoring method takes more than $100 \mathrm{~s}$, which is more than 1.5 times of the former. The former has a better calculation time than the latter. The tangent rate of the traditional dynamic cycle monitoring method changes greatly, especially around 1000 iterations.

It shows that the intelligent assistant method has low demand for hardware and software configuration of the modular data centre, and the amount of redundant data is less, while the traditional dynamic cycle monitoring method has higher requirements on hardware and software and is easy to generate redundant data, which cannot be used for continuous dynamic cycle monitoring of substations.

\section{Conclusion}

A dynamic cycle monitoring method based on an intelligent assistant is proposed. The condition attributes of the configuration object are selected as the research subject. The 30 condition attributes are reduced to 22 . According to "completely belong to a set", "not belong to a set" and "or belong to a set", a sample dynamic cycle monitoring table is constructed. Twenty-two condition attributes are classified and regressed by the information entropy reduction method, and the dynamic cycle monitoring regulation is extracted to judge the information of substation sample configuration points, which has guiding significance for the accuracy diagnosis of configuration point dynamic cycle monitoring. The 22 condition attributes of 16 samples are simulated and analysed, and the consistency between the dynamic cycle monitoring results of 16 test points and the actual survey results is compared. The comparison of the calculation time and accuracy of the dynamic cycle monitoring method based on an intelligent assistant and the traditional dynamic cycle monitoring method shows that the former has higher accuracy and faster calculation.

\section{Acknowledgements}

This work is supported by State Grid Corporation Science and Technology Project (Research on Key Technologies and Business Models of Multi-Station Fusion, 5200-201941477A-0-0-00).

\section{References}

[1] Kailash J K, Sanjay N T. "Face Recognition under Variation of Pose and Illumination using Independent Component Analysis," ICGST-GVIP, 2008, (8):1-6.

[2] Lin K, Chen S C, Chen C S, Lin D D. "Abandoned object detection via temporal consistency modeling and back-tracing verification for visual surveillance," IEEE Transactions on Information Forensics and Security, 2015, 10(7):1359-1370.

[3] Guler P, Emeksiz D, Temizel A, et al. "Real-time multi-camera video analytics system on GPU," Journal of Real-Time Image Processing, 2016, 22(3):457-472. 
[4] Sengar S S, Mukhopadhyay S. "A novel method for moving object detection based on block based frame differencing," 3rd International Conference on Recent Advances in Information Technology, 2016.

[5] Viola P, Jones M. "Robust Real-Time Face Detection," International Journal of Computer Vision, 2004, 57(2):137-154.

[6] Nikan S, Majid A. "Local gradient-based illumination invariant face recognition using local phase quantisation and multi-resolution local binary pattern fusion," IET Image Processing, 2015, 9(1):12-21.
[7] Castillo L E, Cament L A, Galdames F J, Perez C A. "Illumination normalization method using Kolmogorov-Nagumo-based statistics for face recognition," Electronics Letters, 2014, 50(13):940-942.

[8] Zhang F F, Fan R Y, Sun G H, et al. "Research on substation intelligent monitoring scheme under big data environment," Shaanxi Electric Power, 2016, 44 (06):72-76

[9] Tian L. "Development of substation intelligent monitoring system of Wulanchabu Electric Power Bureau," Tianjin University, 2016: Master, 58

[10] Cao Z L. "Research on substation intelligent monitoring scheme under big data environment," China Management Informatization, 2017, 20 (22):53-54 